\title{
FOOD PRODUCTION AND NATIONAL FOOD SECURITY: SITUATION, PROBLEMS AND PROSPECTS
}

\author{
D. Ruscheva* \\ Department "Regional and Sectoral Economy", Economic Research Institute, Bulgarian Academy of \\ Sciences, Sofia, Bulgaria
}

\begin{abstract}
The production of food products in agriculture and the food industry in Bulgaria is important for the formation of the country's food resources, on which the national food security largely depends. The report assesses the situation, presents problems, and substantiates directions for its development in the future in the context of Bulgaria's membership in the European Union and the opportunities to meet the consumption of food products by the population to ensure food security.
\end{abstract}

Key words: production, food, food security.

\section{INTRODUCTION}

Bulgaria has favorable natural and climatic conditions and has accumulated extensive experience in growing various crops and farm animals, as well as the production of basic food products. Their production in agriculture and the food industry is important, as it largely forms the country's food resources. They are essential for the development of its economy, because the food balance and national food security depend on their quantitative, qualitative, assortment and other dimensions. The production of food products in Bulgaria provides raw materials and resources for consumption and export.

Extremely relevant in the current crisis caused by the coronavirus is the issue of food resources of each country, including Bulgaria. The pandemic has focused the attention of the public on rethinking the importance of national production to ensure sustainable and permanent access of the population to food - in sufficient quantities, with the necessary quality characteristics and species diversity.

\footnotetext{
*Correspondence to: Darina Ruscheva, Department "Regional and Sectoral Economy", Economic Research Institute, Bulgarian Academy of Sciences, 3 Aksakov Str., Sofia, E-mail: darinar@abv.bg
}

Changes in the production of food products in Bulgaria can be considered in two directions:in the conditions under which it takes place and in its quantitative dimensions, a prerequisite for its ability to meet their consumption. In the conditions of Bulgaria's membership in the European Union and in connection with the requirements of the Common Agricultural Policy of the European Union (EU CAP), the environment in which the production of food products takes place is significantly changing. Bulgaria has been a full member of the EU since 1 January 2007. Its main instruments are: direct payments and market support for farmers (1st pillar of the CAP) and the Rural Development Program (RDP) (2nd pillar of the CAP). ). During the first programming period (2007-2013), over BGN 7,100 million were received under the direct payments distributed through the Single Area Payment Scheme. Under the EU, the European Agricultural Fund for Rural Development (EAFRD) is the main financial resource for the implementation of rural development policies in Bulgaria, which are implemented by the RDP (2007-2013). The budget of the RDP during this period is EUR 3,241 million, of which EUR 2,609 million are from the EAFRD and EUR 632 million from the state budget. The problems are not so much related to the mechanisms for the absorption of European funds, as to the formulation and positioning of national priorities for the 
development of the agriculture and food production sector, as well as to the development of rural areas. (Bojukliev O. (2016).). During the second programming period, the work on the absorption of European funds continued and the experience gained in recent years related to the organization and implementation of activities under the 1st and 2nd pillars of the EU CAP was further developed. In the new programming period 2021-2027, the EU CAP aims to ensure smart, sustainable and diversified agriculture, care for the environment and climate, and socioeconomic strengthening of rural areas. In the conditions of a pandemic, the development of food production is carried out under changed conditions, mostly related to restrictions, both at the entrance and exit of the production, with regulations regarding transport, raw materials, equipment, people and finished products and fragmentation of the food chain and international relations. The possibilities of production of basic food products in agriculture and the food industry are illustrated by the indicator "degree of commitment", calculated as a ratio of produced and consumed quantities of food products obtained on the basis of the average annual population and consumption of products from households (average per person). The report examines the state of production of basic food products in Bulgaria, highlights problems and substantiates guidelines for its development.

\section{Exposition \\ Trends}

The report assesses trends in the production of basic food products, which are important for the development of the agricultural sector and for the nutrition of the population. What are the trends in the quantitative dimensions of the production of basic food products from the agriculture and food industry of Bulgaria? The results of a study of 33 main food products from these industries (17 from crop production, 3 - from animal husbandry and 13 - from the food industry) show that in 2013, the end of the first programming period, compared to its beginning ( 2007), the following is observed: - in crop production with 10 products $(58.8 \%$ of their total number) production increases. These are cereals - more than twice and sunflower - more than 3 times. The increase in production for fruit species is from $63 \%$ for plums to more than twice for apples and cherries. What is special in this case is that cereals and sunflowers are a large volume of production, while fruit species - it is significantly less and at the same time well below the quantities produced in the past; - the production of livestock products decreased: in milk by $1.6 \%$, in meat by $13.7 \%$ and in eggs - most strongly - by $22.4 \%$; - for 6 products $(46.2 \%)$ produced in the food industry the production increased (meat, fish and fish products, rice, fresh milk, oil and sugar and chocolate products). Reduces the production of canned food (vegetables and fruits), bread and bakery products, some dairy products (cheese, yellow cheese). The comparison of the quantitative dimensions of the production of the observed products in 2016 with those at the beginning of Bulgaria's membership in the EU (2007) allows making the following summaries: - Of the 17 crop products examined, production increased in $11(64.7 \%)$ - again mostly in cereals and sunflower. The increase in the production of fruit crops (apples - by $71.0 \%$, apricots - by $86.7 \%$, cherries and plums - more than 2 times) deserves a positive assessment. Compared to 2007, the production of the other 6 agricultural crops decreased (35.3\%), reaching: beans $-35.1 \%$, potatoes $42.6 \%$, wine grapes $-58.4 \%$, dessert grapes $74,3 \%$, strawberries $-85.0 \%$ and pepper $88.1 \%$ of what was obtained in the base year. The main reason for this is the reduction of the areas occupied by these crops; - decreased meat production, reaching respectively $(90.1 \%)$ compared to the level in 2007 , milk $(86.5 \%)$ and eggs $(84.3 \%)$. The reason is primarily a decrease in the number of farm animals in all species - from $92.6 \%$ in cattle to $47.9 \%$ - in goats. There is an exception only for buffaloes, which increased compared to 2007 by $2.1 \%$; - in $7(53.8 \%)$ of the products of the food industry the production increases. These are meat, fish and fish products, rice, fresh milk, yogurt, cheese and oil. In $6(46.2 \%)$ of the products the production decreased: bread and bakery products, meat products, yellow cheese, canned vegetables, canned fruits and sugar and chocolate products. The decrease was the largest in yellow cheese (by 26.1\%) and the smallest - in canned vegetables (by 7.4\%).

Despite the outlined changes in the quantitative dimensions of production, its domestic product structure remains relatively stable, maintaining the leading position in: cereals of wheat, 
vegetables - tomatoes; in the case of grapes of wine grapes; in the case of meat - of poultry meat; in the case of milk, cow's milk. The changes in the structure of production of fruit species are expressed in the fact that apples give way to the leading place (their relative share in 2007 was $27.7 \%$ ) to plums, which in 2016 had a relative share of 27.3 percent.

\section{Opportunities for production to meet the consumption of food products}

It is interesting to assess how the possibilities for the production of basic food products from agriculture and the food industry are changing their consumption. This idea is illustrated on the basis of 19 products - 7 from agriculture and 12 from the food industry. In 2007 , only 4 products $(21.0 \%$ of their total number) exceeded their consumption. These are: yellow cheese (by 23.5\%), pepper (by $33.3 \%$ ), potatoes (by $42.8 \%$ ) and sugar and chocolate products (by 97.3\%). For the remaining $15(79,0 \%)$ domestic production in the country cannot fully satisfy the consumption of basic food products. In 2013, the number of products decreased insignificantly from 4 to 3 , where production can cover their consumption. These are: oil, sugar and chocolate products and pepper. For the remaining $16(84.3 \%)$ products, the picture is definitely associated with food deficits. In 2016, there are again 4 products for which production is above their consumption - meat products, oil, pepper and sugar and chocolate products. For the remaining 15 (78.9\%) production cannot satisfy their consumption.

The following can be summarized for the observed three years: - in all three years only for two products pepper and sugar and chocolate products, invariably the production is able to satisfy their consumption.

- in the group for which the production can ensure their consumption during the evaluated years the picture is different: a) for potatoes and for yellow cheese - only in 2007 the production is able to satisfy their consumption; b) for oil - in 2007 there is underproduction, which is overcome in the remaining two years and c) for meat products and canned vegetables, the underproduction in 2007 and in 2013 is overcome only in 2016; - for other basic foodstuffs, production cannot permanently satisfy their subsistence. Organic production will become increasingly important. A very important factor influencing the growth of organic farming is the growth of the market value of organic production and especially the growth of demand for organic products. In general, it is obvious that organic farming is a specific market niche in the world and European agricultural markets. Its development is especially related to the new trends in consumption, as well as to the growth of the economy of the individual countries and especially to the growth of the per capita income in the individual countries. (Branzova, P. (2019)).

\section{Problems}

1. Long-standing, sustained downward trends in the production of important food products from agriculture and the food industry continue to emerge.

2. There is a strong development in intensive cereals and sunflower. This is the expense of the development of vegetable and fruit growing, as well as the production of raw materials and livestock products. 3. Reduce the raw materials for the processing industry (meat, milk, grapes, etc.); resources for domestic consumption (potatoes, beans, peppers, strawberries, etc.) and for exports are limited and this has a negative impact on national food security. Moreover, we are talking about agricultural crops for which there are favorable natural and climatic conditions for cultivation, historical experience in their production and opportunities in terms of the size of their production, realized in the past in the country.

4. Food shortages arise. Some of them can be covered by production in households, which is especially important for people in the villages and small towns of Bulgaria. In the conditions of shrinking production, unemployment and low incomes, it becomes one of the sources for food consumption of the population. But domestic production should only be seen as an additional source of food. Today, part of the food deficits are covered by imports, while in the past the object of import were mainly products for which there are no suitable natural resources for their cultivation in the country. 5. However, the "entry" of imported products on the Bulgarian food market is associated with problems in terms of quality control, undermining the production of small and medium-sized agricultural producers in our country and others.

6. In the context of a pandemic, when borders are closed, it has become clear that it is 
impossible to rely on imports to cover food deficits.

7. The pandemic also posed problems for ensuring the nutrition of the population of certain regions and districts, relying on its own food resources, the cultivation of local varieties and breeds of farm animals, the production of quality products that take into account local taste preferences of consumers. 8. Despite the progress and the significant financial resources coming through the European funds, there is no positive impact on the quantitative dimensions of food production and the resulting deficits.

\section{Perspectives}

Prospects for the production of food products in Bulgaria, considered in the context of Bulgaria's membership in the EU and national food security should be considered in: 1. Creation of appropriate conditions (economic, technical, technological, infrastructural, etc.) for overcoming the longstanding, permanently formed tendency of reduction of the quantities and for their further increase.

2. Taking into account the favorable natural and climatic conditions and parameters of agricultural production and production in the food industry at the end of the 20th century, it follows that production must develop in the direction of full use of natural and productive potential, ensuring environmental protection at the entrance and exit. 3. The production should be connected both with the necessary resources for its realization and with the food needs of the society. 4. The production of quality food products helps to increase their competitiveness on the domestic and international markets. It is a pledge for higher health status and improving the quality of life of the population in Bulgaria. 5. The conducted agrarian policy in Bulgaria must be aimed at guaranteeing the national food security. It is necessary for the prospects
For the development of the production of food products to be outlined in the National Food Policy of Bulgaria, in which the issues of providing resources, production parameters and opportunities for satisfying the consumption of basic food products should be interconnected.

\section{CONCLUSION}

The production of basic food products in Bulgaria should be developed in such a way as to overcome the emerging food deficits, to adapt to the changing conditions of the external environment and to the requirements of the consumers, to increase the competitiveness of the Bulgarian food products to the domestic and international food products markets, full use of the country's natural resources for the production of more and better products.

\section{ACKNOWLEDGMENTS}

This work was supported by the Bulgarian Ministry of Education and Science under the National Research Programme „Healthy Foods for a Strong Bio-Economy and Quality of Life" approved by DCM \# 577/ 17.08.2018".

\section{REFERENCES}

1. Statistical Yearbook of Bulgaria. 2. Budgets of households in Bulgaria.

2. Bojukliev O. (2016). Focus: Agricultures Sector as a factor for the Economic Development of Bulgaria. Annual Report 2016. Economic Development and Policies in Bulgaria: Evaluations and Prospects. Sofia. Gorex Press. pp. 182.

3. Branzova, P. (2019). Vlyanie na klimatichnite promeni vurhu razvitieto na osnovni ovoshtni kulturi $\mathrm{v}$ Ugoiztochen raion na Bulgaria, Izdatelstvo Roll Kumpuni, Sofia, pp. 146. 